\title{
PEMBINAAN GURU MATEMATIKA SMA DALAM MENYUSUN SILABUS BERKARAKTER MELALUI LOKAKARYA
}

\author{
Nur Isnaini Taufik \\ Pengawas SMA/SMK Dinas Pendidikan Kab. Ogan Komering Ulu \\ Prov. Sumatera Selatan, nurisnainitaufik@gmail.com
}

\begin{abstract}
ABSTRAK
Implementasi pendidikan karakter dalam kurikulum meliputi: (1) integrasi dalam mata pelajaran, (2) integrasi dalam muatan lokal, dan (3) integrasi dalam kegiatan pengembangan diri. Sedangkan integrasi pendidikan karakter dalam mata pelajaran yaitu mengembangkan silabus dan Rencana Pelaksanaan Pembelajaran (RPP) pada kompetensi yang telah ada sesuai dengan nilai yang akan diterapkan. Oleh karena itu, tujuan penulisan ini adalah: (1) menginformasikan kepada guru matematika tentang cara menyusun silabus matematika SMA berkarakter, dan (2) memberi cara alternatif pembinaan guru matematika oleh pengawas akademik matematika dalam menyusun silabus matematika berkarakter melalui lokakarya di SMA. Lokakarya merupakan pertemuan ilmiah yang kecil, bersifat kelompok, dan dapat melibatkan beberapa guru matematika SMA dalam satu kabupaten, dengan tujuan untuk memecahkan suatu masalah-misalnya masalah dalam penyusunan silabus matematika SMA berkarakter. Kegiatan penyusunan silabus matematika SMA berkarakter dalam bentuk lokakarya sebaiknya menggunakan berbagai metode pembelajaran. Dalam makalah ini diuraikan tentang: (1) penyusunan silabus matematika SMA berkarakter, dan (2) alternatif pembinaan guru matematika oleh pengawas akademik matematika dalam menyusun silabus matematika SMA berkarakter melalui lokakarya.
\end{abstract}

Kata Kunci: pembinaan guru, menyusun silabus berkarakter, lokakarya.

\begin{abstract}
Implementation of character education in the curriculum include: (1) integration of subjects, (2) integration of local content, and (3) the integration of the activities of selfdevelopment. While the integration of character education in subjects that develop the syllabus and Lesson Plan on existing competence in accordance with the value that will be applied. Therefore, the purpose of this paper is: (1) inform the teacher of mathematics on how to prepare a high school mathematics syllabus character, and (2) provide an alternative way math teacher coaching by the academic supervisor of mathematics in developing mathematics syllabus character through workshops in high school. The workshop is a scientific meeting that small, character group, and may involve some high school math teacher in the district, with the aim to solve a problem-for example, problems in the preparation of high school mathematics syllabus character. In this paper elaborated on: (1) preparation of high school mathematics syllabus character, and (2) the alternative math teacher coaching by the academic supervisor of mathematics in high school mathematics syllabus compiled character through workshops.
\end{abstract}

Keywords: coaching teachers, preparing a syllabus character, workshop.

\section{Pendahuluan}

Pembangunan karakter yang Pancasila dan Pembukaan UUD 1945 merupakan upaya perwujudan amanat dilatarbelakangi oleh realita 
permasalahan kebangsaan yang berkembang saat ini, seperti: disorientasi dan belum dihayatinya nilai-nilai Pancasila; keterbatasan perangkat kebijakan terpadu dalam mewujudkan nilai-nilai Pancasila; bergesernya nilai etika dalam kehidupan berbangsa dan bernegara; memudarnya kesadaran terhadap nilai-nilai budaya bangsa; ancaman disintegrasi bangsa; dan melemahnya kemandirian bangsa (Pemerintah RI, 2010:16-19).

Pendidikan budaya dan karakter bangsa pada dasarnya adalah pengembangan nilai-nilai yang berasal dari pandangan hidup atau ideologi bangsa Indonesia, agama, budaya, dan nilai-nilai yang terumuskan dalam tujuan pendidikan nasional. Menyadari pentingnya nilai budaya dan karakter bangsa, banyak pihak menuntut peningkatan intensitas dan kualitas pelaksanaan pendidikan karakter pada lembaga pendidikan formal. Hal tersebut didasarkan pada fenomena sosial yang berkembang yaitu meningkatnya kenakalan remaja dalam masyarakat seperti perkelahian massal dan berbagai kasus dekadensi moral lainnya. Oleh karena itu lembaga pendidikan formal sebagai wadah resmi pembinaan generasi muda diharapkan dapat meningkatkan peranannya dalam pembentukan kepribadian siswa melalui peningkatan intensitas dan kualitas pendidikan karakter. Agar siswa memiliki karakter mulia sesuai norma-norma agama, hukum, tata krama, budaya, dan adat istiadat, maka perlu dilakukan pendidikan nilai budaya dan karakter bangsa secara memadai (Prayitno \& Widyantini, 2011: 1-14).

Implementasi pendidikan karakter dalam kurikulum meliputi: (1) integrasi dalam mata pelajaran, (2) integrasi dalam muatan lokal, dan (3) integrasi dalam kegiatan pengembangan diri. Sedangkan integrasi pendidikan karakter dalam mata pelajaran meliputi: (1) mengembangkan silabus dan Rencana Pelaksanaan Pembelajaran (RPP) pada kompetensi yang telah ada sesuai dengan nilai yang akan diterapkan (Kemdiknas, 2011: 14). Penyusunan silabus dan RPP berkarakter dapat dilakukan oleh guru secara mandiri atau berkelompok dalam sebuah sekolah atau beberapa sekolah, kelompok Musyawarah Guru Mata Pelajaran (MGMP) dan Dinas Pendidikan. Didapat data dari temuan di sekolah, ternyata: (1) banyak guru yang hanya mengcopy silabus dan RPP matematika dari guru lain atau mengunduh dari internet, (2) banyak guru yang tidak menyusun silabus dan RPP matematika berkarakter.

Berdasarkan latar belakang di atas, maka diambil rumusan masalah sebagai berikut: "(1) Apa informasi yang diberikan kepada guru matematika tentang cara menyusun silabus matematika SMA yang berkarakter, dan (2) Bagaimana memberikan pembinaan 
terhadap guru matematika oleh pengawas akademik matematika dalam menyusun silabus berkarakter melalui lokakarya di SMA? Sesuai dengan rumusan masalah, maka tujuan dari tulisan ini adalah: (1) menginformasikan kepada guru matematika tentang cara menyusun silabus matematika SMA berkarakter, dan (2) memberi cara alternatif pembinaan guru matematika oleh pengawas akademik matematika dalam menyusun silabus matematika berkarakter melalui lokakarya di SMA.

\section{Kajian Teori}

Pembinaan diartikan sebagai perihal membina atau pembaruan; penyempurnaan (Depdiknas, 2008a: 202). Jadi, pembinaan guru matematika diartikan sebagai perihal membina guru matematika supaya lebih baik (maju, sempurna, dsb). Pada makalah ini dibahas pembinaan guru matematika dalam menyusun silabus matematika berkarakter melalui lokakarya di SMA.

Silabus merupakan acuan penyusunan kerangka pembelajaran untuk setiap bahan kajian mata pelajaran. Silabus paling sedikit memuat: a. Identitas mata pelajaran (khusus SMP/MTs/ SMPLB/Paket B dan SMA/MA/SMALB/SMK/MAK/Paket

C/Paket C Kejuruan); b. Identitas sekolah meliputi nama satuan pendidikan dan kelas; c. kompetensi inti, merupakan gambaran secara kategorial mengenai kompetensi dalam aspek sikap, pengetahuan, danketerampilan yang harus dipelajari peserta didik untuk suatu jenjang sekolah, kelas dan mata pelajaran; d. kompetensi dasar, merupakan kemampuan spesifik yang mencakup sikap, pengetahuan, dan keterampilan yang terkait muatan atau mata pelajaran;e. tema (khusus SD/MI/SDLB/ Paket A); f. materi pokok, memuat fakta, konsep, prinsip, dan prosedur yang relevan, dan ditulis dalam bentuk butir-butir sesuai dengan rumusan indikator pencapaian kompetensi; g. pembelajaran,yaitu kegiatan yang dilakukan oleh pendidik dan peserta didik untuk mencapai kompetensi yang diharapkan; h. penilaian, merupakan proses pengumpulan dan pengolahan informasi untuk menentukan pencapaian hasil belajar peserta didik; i. alokasi waktu sesuai dengan jumlah jam pelajaran dalam struktur kurikulum untuk satu semester atau satu tahun; dan j. sumber belajar, dapat berupa buku, media cetak dan elektronik, alam sekitar atau sumber belajar lain yang relevan. Silabus dikembangkan berdasarkan Standar Kompetensi Lulusan dan Standar Isi untuk satuan pendidikan dasar dan menengah sesuai dengan pola pembelajaran pada setiap tahun ajaran tertentu.Silabus digunakan sebagai acuan dalam pengembangan rencana pelaksanaan pembelajaran (Permendikbud No. 65 tahun 2013). 
Karakter adalah watak, tabiat, akhlak, atau kepribadian seseorang yang terbentuk dari hasil internalisasi berbagai kebajikan (virtues) yang diyakini dan digunakan sebagai landasan untuk cara pandang, berpikir, bersikap, dan bertindak. Interaksi seseorang dengan orang lain menumbuhkan karakter masyarakat dan karakter bangsa. Pengembangan budaya dan karakter bangsa dalam pembelajaran dilakukan secara terpadu, melalui perencanaan yang baik, pendekatan yang sesuai, metode belajar dan pembelajaran yang efektif. Pendidikan budaya dan karakter bangsa pada dasarnya adalah pengembangan nilai-nilai yang berasal dari pandangan hidup atau ideologi bangsa Indonesia, agama, budaya, dan nilai-nilai yang terumuskan dalam tujuan pendidikan nasional (Prayitno \& Widyantini, 2011:13-14).

Pendidikan karakter disebutkan sebagai pendidikan nilai, pendidikan budi pekerti, pendidikan moral, pendidikan watak yang bertujuan mengembangkan kemampuan peserta didik untuk memberikan keputusan baik-buruk, memelihara apa yang baik, dan mewujudkan kebaikan itu dalam kehidupan sehari-hari dengan sepenuh hati (Kemdiknas, 2011:5-6).

Menurut Puskur (Kemdiknas, 2010:9-10) dinyatakan bahwa teridentifikasi 18 macam nilai-nilai yang perlu dikembangkan dalam pendidikan budaya dan karakter bangsa, yaitu: (1) Religius, (2) Jujur, (3) Toleransi, (4) Disiplin, (5) Kerja keras, (6) Kreatif, (7) Mandiri, (8) Demokratis, (9) Rasa Ingin Tahu, (10) Semangat Kebangsaan, (11) Cinta Tanah Air, (12) Menghargai Prestasi, (13) Bersahabat/Komunikatif, (14) Cinta Damai, (15) Gemar Membaca, (16) Peduli Lingkungan, (17) Peduli Sosial, (18) Tanggung Jawab.

Nilai karakter yang disarikan dari butir-butir SKL dinamakan nilai karakter pokok, yaitu kereligiusan, kejujuran, kecerdasan, ketangguhan, kedemokratisan dan kepedulian yang ditanamkan melalui semua mata pelajaran. Sedangkan nilai karakter utama pada mata pelajaran matematika adalah nilai-nilai yang paling dekat dengan karakteristik mata pelajaran matematika, terdiri atas: berpikir logis, kritis, kreatif dan inovatif, kerja keras, keingintahuan, kemandirian dan percaya diri (Prayitno \& Widyantini, 2011: 31).

Lokakarya adalah pertemuan antar ahli dengan maksud untuk membahas suatu masalah dalam bidang keahliannya. Lokakarya disebut juga sanggar kerja (Depdiknas, 2008a: 872). Workshop atau lokakarya merupakan salah satu metode yang dapat ditempuh pengawas sekolah dalam melakukan supervisi manajerial (Depdiknas, 2008b: 21).

Lokakarya atau dalam bahasa Inggris disebut workshop adalah suatu 
acara di mana beberapa orang berkumpul untuk memecahkan masalah tertentu dan mencari solusinya. Sebuah lokakarya atau workshop adalah pertemuan ilmiah yang kecil. Sekelompok orang yang memiliki perhatian yang sama berkumpul bersama di bawah kepemimpinan beberapa orang ahli untuk menggali satu atau beberapa aspek khusus suatu topik. Sub-sub kelompok dibentuk untuk tujuan mendengarkan ceramah-ceramah, melihat demonstrasi-demonstrasi, mendiskusikan berbagai aspek topik, mempelajari, mengerjakan, mempraktekkan, dan mengevaluasinya. Sebuah lokakarya biasanya terdiri dari pimpinan lokakarya, anggota, dan narasumber (Aff, Anas, 2015).

Lokakarya bertujuan untuk memberi-kan informasi atau panduan, serta berfokus pada pengajaran keterampilan khusus atau pembahasan topik tertentu. Lokakarya bisa hanya berlangsung selama satu atau dua jam atau bisa juga berlangsung bermingguminggu tergantung pada topiknya. Pemimpin lokakarya dapat memperkuat efektivitas presentasi mereka melalui perencanaan yang matang, pengorganisasian yang baik serta praktik presentasi (http://id.wikihow.com/ Menyiapkan-Lokakarya).

\section{Pembahasan}

Silabus memuat Standar Kompetensi (SK)/Kompetensi Inti (KI), Kompetensi Dasar (KD), materi pembelajaran, kegiatan pembelajaran, indikator pencapaian, penilaian, alokasi waktu, dan sumber belajar. Materi pembelajaran, kegiatan pembelajaran, indikator pencapaian, penilaian, alokasi waktu, dan sumber belajar yang dirumuskan di dalam silabus pada dasarnya ditujukan untuk memfasilitasi siswa menguasai SK/KD. Agar juga memfasilitasi terjadinya pembelajaran yang membantu siswa mengembangkan karakter, setidak-tidaknya perlu dilakukan perubahan pada tiga komponen silabus berikut: (1) penambahan dan/atau modifikasi kegiatan pembelajaran, (2) penambahan dan/atau modifikasi indikator pencapaian kompetensi, dan (3) penambahan dan/atau modifikasi teknik penilaian. Penambahan dan/atau adaptasi kegiatan pembelajaran, indikator pencapaian, dan teknik penilaian harus memperhatikan kesesuaiannya dengan SK dan KD yang harus dicapai oleh siswa. Kegiatan pembelajaran, indikator pencapaian, dan teknik penilaian yang ditambahkan dan/atau hasil modifikasi tersebut harus bersifat lebih memperkuat pencapaian SK dan KD tetapi sekaligus mengembangkan karakter (Kemdiknas, 2010: 45-46). 


\section{CONTOH FORMAT SILABUS PEMBELAJARAN}

$\begin{array}{ll}\text { Nama Sekolah } & \text { : SMA .......................... MATEMATIKA } \\ \text { Mata Pelajaran } & \text { : M / UMUM } \\ \text { Kelas / Program } & : \text { GANJIL }\end{array}$

Sandar Kompetensi : 1. Memecahkan masalah yang berkaitan dengan bentuk pangkat, akar, dan logaritma

\begin{tabular}{|c|c|c|c|c|c|c|c|c|c|c|}
\hline \multirow[b]{2}{*}{$\begin{array}{c}\text { Kompetensi } \\
\text { Dasar }\end{array}$} & \multirow[b]{2}{*}{$\begin{array}{c}\text { Materi } \\
\text { Ajar }\end{array}$} & \multirow[b]{2}{*}{$\begin{array}{c}\text { Nilai } \\
\text { Budaya } \\
\text { Dan } \\
\text { Karakter } \\
\text { Bangsa }\end{array}$} & \multirow[b]{2}{*}{$\begin{array}{c}\text { Kewira- } \\
\text { usahaan/ } \\
\text { Ekonomi } \\
\text { Kreatif }\end{array}$} & \multirow[b]{2}{*}{$\begin{array}{c}\text { Kegiatan } \\
\text { Pembela- } \\
\text { jaran }\end{array}$} & \multirow[b]{2}{*}{$\begin{array}{l}\text { Indikator } \\
\text { Penca- } \\
\text { paian } \\
\text { Kompe- } \\
\text { tensi }\end{array}$} & \multicolumn{3}{|c|}{ Penilaian } & \multirow[b]{2}{*}{$\begin{array}{l}\text { Alokasi } \\
\text { Waktu } \\
\text { (menit) }\end{array}$} & \multirow[b]{2}{*}{$\begin{array}{c}\text { Sumber } \\
\text { /Bahan/ } \\
\text { Alat }\end{array}$} \\
\hline & & & & & & $\begin{array}{c}\text { Tek- } \\
\text { nik }\end{array}$ & $\begin{array}{c}\text { Bentuk } \\
\text { Instru- } \\
\text { men }\end{array}$ & $\begin{array}{l}\text { Contoh } \\
\text { Instru- } \\
\text { men }\end{array}$ & & \\
\hline
\end{tabular}

Ada dua rekomendasi dalam pengembangan silabus yang diintegrasikan dengan nilai-nilai karakter, yaitu: (1) kegiatan pembelajaran, indikator pencapaian kompetensi serta teknik penilaian pada silabus pembelajaran harus bersifat memperkuat pencapaian SK dan KD tetapi sekaligus mengembangkan karakter; (2) pada silabus, nilai-nilai karakter yang hendak ditanamkan dan dikembangkan pada diri siswa dapat ditulis pada bagian atau kolom tersendiri dan kegiatan pembelajaran yang menguatkan penanaman nilai-nilai tersebut ditandai atau diketik dengan huruf tebal (Prayitno \& Widyantini, 2011: 38). Pencantuman nilai-nilai karakter pada silabus dapat ditempatkan pada kolom sebelah kanan kompetensi dasar, atau pada kolom paling kanan setelah sumber belajar.

Kegiatan lokakarya biasanya diselenggarakan oleh suatu gugus Kelompok Kerja Guru (KKG) di kecamatan - untuk SD; atau oleh Musyawarah Guru Mata Pelajaran
(MGMP) di kabupaten - untuk tingkat SMP, SMA, dan SMK; atau lokakarya yang diselenggarakan oleh Dinas Pendidikan. Misalnya, kegiatan tersebut berjudul "Lokakarya Pengembangan Silabus Matematika SMA Berkarakter." Pengawas sekolah sebagai narasumber dalam lokakarya harus menyiapkan sumber bahan yaitu berupa makalah lengkap tentang penyusunan silabus matematika SMA berkarakter dan powerpoint (ppt)-nya. Agar mencapai hasil yang sebaik-baiknya dalam lokakarya ini, maka dapat digunakan berbagai metode, misalnya menggunakan metode ceramah, tanya jawab, metode diskusi kelompok, dan metode diskusi kelas. Lokakarya juga dapat menggunakan metode pemecahan masalah yang berbentuk "musyawarah dan penyelidikan" (Aff, Anas, 2015).

Berikut adalah langkah-langkah untuk mempersiapkan sebuah lokakarya, terdiri dari: (1) merencanakan lokakarya, (2) menyiapkan bahan pendukung lokakarya, dan (3) mendorong partisipasi 
peserta lokakarya. Pertama, merencanakan lokakarya, meliputi: (1) menentukan tujuan lokakarya; menentukan apa yang menjadi kebutuhan peserta lokakarya; (3) membuat rancangan presentasi lokakarya; (4) menentukan perkiraan alokasi waktu untuk masing-masing sesi acara pada rancangan lokakarya; dan (5) setelah Anda menyelesaikan rancangan lokakarya, praktiklah untuk memberikan presentasi. Kedua, menyiapkan bahan pendukung lokakarya, meliputi: (1) mempersiapkan handout (suatu naskah tulisan yang mendukung, mengembangkan, mengelola atau paling tidak menyediakan tindak lanjut dari suatu pelatihan) untuk peserta; (2) menggunakan alat peraga visual; dan (3) menggunakan perangkat berbasiskan situs web, jika bisa diterapkan. Ketiga, mendorong partisipasi peserta lokakarya, meliputi: (1) mengatur ruang sedemikian rupa sehingga nyaman untuk diskusi; (2) memasukkan kegiatan interaktif ke dalam lokakarya; dan (3) menyertakan sesi tanya jawab (http://id.wikihow.com/ Menyiapkan-Lokakarya).

Langkah-langkah kegiatan dalam lokakarya penyusunan silabus matematika SMA berkarakter meliputi: (1) dengan metode ceramah dan tanya jawab, narasumber dan guru merumuskan: a) tujuan lokakarya (output yang akan dicapai), misalnya tersusunnya silabus matematika SMA berkarakter, b) pokok-pokok masalah yang akan dibahas secara terperinci, dan c) prosedur pemecahan masalah; (2) dengan metode ceramah dan tanya jawab, guru diberi pengertian tentang pendidikan budaya dan karakter bangsa yang dapat diintegrasikan pada mata pelajaran matematika SMA; (3) kelas dibagi menjadi beberapa kelompok dan masingmasing kelompok diberikan contoh silabus matematika SMA berkarakter; (4) dengan diskusi kelompok, guru-guru membuat silabus matematika SMA berkarakter bersama-sama dalam kelompoknya, sedangkan narasumber berkeliling memberikan bantuan seperlunya; (5) dengan diskusi kelas, masing-masing kelompok mempresentasikan hasilnya di depan kelas, sedangkan peserta lain menanggapinya; (6) narasumber memberikan saran dan pengarahan terhadap hasil presentasi; dan (7) narasumber bersama-sama dengan guru membuat kesimpulan terhadap hasil diskusi tentang pembuatan silabus matematika berkarakter.

Metode lokakarya dipilih karena memiliki beberapa keunggulan, yaitu: (1) memberi kebebasan berargumen kepada peserta lokakarya dan pemakalah; (2) memberi peluang melibatkan banyak peserta; (3) menyerap informasi sebanyak mungkin untuk suatu hasil atau perubahan konsep semula sehingga ide pemakalah akan diuji dan mendapat 
tanggapan tentang kelebihan dan kekurangan dari ide pemakalah; (4) dapat digunakan sebagai referensi bagi pengamat dan pemegang kebijakan, baik masyarakat umum dan pemerintah (Aff, Anas, 2015).

\section{Kesimpulan}

Dari uraian di atas, maka penulis mengambil simpulan di bawah ini.

1. Nilai-nilai utama budaya dan karakter bangsa untuk mata pelajaran matematika

SMA adalah berpikir logis, kritis, kerja keras, keingintahuan, kemandirian, percaya diri. Nilai-nilai pokok mata pelajaran matematika SMA adalah kereligiusan, kejujuran, cerdas, tangguh, peduli dan demokratis.

2. Pengintegrasian nilai-nilai budaya dan karakter bangsa dalam mata pelajaran matematika SMA pada tahap perencanaan pembelajaran dapat dilaksanakan dalam silabus dan RPP matematika SMA dengan mengadaptasi tiga komponen berikut sehingga bermuatan karakter, yaitu: (a) penambahan dan/atau modifikasi kegiatan pembelajaran, penambahan dan/atau modifikasi indikator pencapaian, dan (c) penambahan dan/ atau modifikasi teknik penilaian.

3. Langkah-langkah untuk mempersiapkan sebuah lokakarya, yaitu: (1) merencanakan lokakarya,

menyiapkan bahan pendukung lokakarya, dan (3) mendorong partisipasi peserta lokakarya. Kegiatan penyusunan silabus matematika SMA berkarakter dalam bentuk lokakarya sebaiknya menggunakan berbagai metode pembelajaran, misalnya menggunakan metode ceramah, tanya jawab, metode diskusi kelompok, dan metode diskusi kelas, atau metode pemecahan masalah.

\section{Pustaka}

Aff, Anas. 2015. Jenis Workshop. Tersedia pada http://www.scribd.com/doc/ 112941893/1-Jenis-Workshop\# scribd. Diakses pada 20-4-2015.

Depdiknas. 2008a. Kamus Bahasa Indonesia. Jakarta: Pusat Bahasa. 2008b. Metode dan

Teknik Supervisi. Jakarta: Dit. Tendik Ditjend. PMPTK.

Kemdikbud. 2013. Permendikbud RI No.

65 Tahun 2013 tentang Standar Proses.

Kemdiknas. 2010. Panduan Pendidikan Karakter di Sekolah Menengah Pertama. Jakarta: Direktorat Pembinaan SMP. 2011. Panduan

Pelaksanaan Pendidikan 
Karakter. Jakarta: Puskurbuk Balitbang.

Pemerintah RI. 2010. Kebijakan Nasional Pembangunan Karakter Bangsa Tahun 2005-2025.
Prayitno \& Widyantini. 2011. Pendidikan Nilai-nilai Budaya dan Karakter Bangsa dalam Pembelajaran Matematika di SMP. Yogyakarta: PPPPTK Matematika. 
